\title{
Using soil sensing technology to examine interactions and controls between ectomycorrhizal growth and environmental factors on soil $\mathrm{CO}_{2}$ dynamics
}

\author{
Niles J. Hasselquist • Rodrigo Vargas • \\ Michael F. Allen
}

Received: 3 June 2009 / Accepted: 24 September 2009 /Published online: 14 October 2009

(C) The Author(s) 2009. This article is published with open access at Springerlink.com

\begin{abstract}
Soils play a critical role in the global carbon cycle, yet the biophysical factors regulating soil $\mathrm{CO}_{2}$ dynamics remain unclear. We combined high-frequency in situ observations of fine roots and ectomycorrhizal (EM) fungi with data from multiple soil sensor arrays to examine the biophysical interactions influencing soil $\mathrm{CO}_{2}$ production for one year in a mixed conifer forest. Using structural equation modeling we constructed a hypothesized model to test for causal interactions among environmental factors, biotic factors, and soil $\mathrm{CO}_{2}$ dynamics throughout the soil profile. According to our model, seasonal variation in $\mathrm{CO}_{2}$ production was significantly influenced by EM rhizomorph production, soil temperature, and soil moisture. Fine root production, on the other hand, did not appear to significantly influence soil $\mathrm{CO}_{2}$ production. The relationship between EM rhizomorph production and soil $\mathrm{CO}_{2}$ production was also supported by a zero temporal lag between these
\end{abstract}

Responsible Editor: Erik A. Hobbie.

N. J. Hasselquist $(\bowtie) \cdot$ M. F. Allen

Center for Conservation Biology,

University of California-Riverside,

University Laboratory Building Room 208,

Riverside CA, 92521, USA

e-mail: nhass001@ucr.edu

R. Vargas

Department of Environmental Science Policy and Management, University of California,

Berkeley, CA 94720, USA two measurements in a cross-correlation analysis. In contrast, $\mathrm{CO}_{2}$ production increased before fine root production suggesting that these two measurements were decoupled in time. Results from this study highlight the need to better understand differences in carbon allocation between plant roots and EM fungi to improve our predictions of soil carbon dynamics under global climate change.

Keywords Ectomycorrhizal rhizomorphs · Fine roots · Minirhizotron - Soil $\mathrm{CO}_{2}$ production - Soil sensors ·

Structural equation model

\section{Introduction}

Soils are of particular importance in the global carbon cycle because they contain more carbon than live biomass (Eswaran et al. 1993), and the efflux of $\mathrm{CO}_{2}$ from the soil surface $\left(\mathrm{R}_{\mathrm{s}}\right)$ represents a major flux of carbon into the atmosphere (Raich and Schlesinger 1992, Schlesinger and Andrews 2000). Previously, $R_{s}$ has been reported to represent $40-80 \%$ of total ecosystem respiration (Law et al. 1999, Janssens et al. 2001). It is therefore crucial to understand the biotic factors influencing $\mathrm{R}_{\mathrm{s}}$ as well as how these factors are affected by seasonal changes in environmental conditions in order to accurately estimate $R_{\mathrm{s}}$. However, understanding the interactions between environmental factors, biotic factors, and $R_{s}$ is complex and involves the product of numerous 
biophysical interactions (Stoyan et al. 2000, Davidson et al. 2006). In this study, we combined in situ observations of fine roots and ectomycorrhizal (EM) fungi with continuous data from multiple soil sensor arrays (Allen et al. 2007) in order to examine the interactions between environmental factors, biotic factors, and $\mathrm{CO}_{2}$ dynamics throughout the soil profile.

The importance of biotic factors for $R_{s}$ has frequently been divided between autotrophic respiration (generally referred to as root respiration) and heterotrophic respiration (respiration from decomposers). Roots are the primary belowground structural element of plants and have previously been reported as major factors influencing the autotrophic component of $\mathrm{R}_{\mathrm{s}}$ (Ewel et al. 1987, Edwards 1991, Bowden et al. 1993, Boone et al. 1998). Autotrophic respiration can account for as little as $10 \%$ or greater than $90 \%$ of total in situ $R_{S}$ depending on vegetation type and season of the year (Hanson et al. 2000). However, autotrophic respiration is not limited to plant roots. Within hours, recently fixed carbon is transported to EM fungi (Söderström and Read 1987, Högberg et al. 2008), the symbiotic associates of woody plants. Consequently, autotrophic respiration should be considered as a combination of both root respiration and EM fungal respiration. Difficulties in separating root respiration from fungal respiration have resulted in EM fungal respiration being included with root respiration, and only recently have researchers begun to separate and identify the importance of EM fungi for $\mathrm{R}_{\mathrm{S}}$ (Fahey et al. 2005, Langley et al. 2005, Heinemeyer et al. 2007, Vargas and Allen 2008a, b). For example, Heinemeyer et al. (2007) used a mycorrhizal mesh collar design and found that EM hyphae contributed $\sim 25 \%$ to $\mathrm{R}_{\mathrm{s}}$ in a lodgepole pine forest.

Ectomycorrhizal fungi are the dominant mycorrhizal partners in boreal and north temperate forests, mediating the flux of nutrients and water from soils to their host plants in exchange for host carbohydrates (Read 1991). The vast majority of nutrient-absorbing surface area for plants in these regions resides with EM fungi, and up to $20 \%$ of net primary production is estimated to flow through EM fungi to maintain this surface area (Treseder and Allen 2000). The morphology of EM hyphae is often complex, ranging from individual hyphae to cords that form rhizomorphs and act like vessel elements in plants, transporting water for distances up to several meters (Duddridge et al. 1980). In semi-arid mixed conifer forests, such as our research site, EM associations might be extremely important because EM rhizomorphs can extend several meters into the surrounding soil matrix in search for patches of nutrients and water otherwise unavailable to non-mycorrhizal plants (Allen 2007). Although recent studies have shown the importance of fine roots and EM fungi for $\mathrm{R}_{\mathrm{S}}$ (Fahey et al. 2005, Langley et al. 2005, Heinemeyer et al. 2007, Vargas and Allen 2008a, b), we still do not have a good mechanistic understanding of the biophysical interactions influencing $\mathrm{CO}_{2}$ dynamics throughout the soil profile.

Recent developments in automated measurements of $\mathrm{R}_{\mathrm{s}}$ are generating increasing numbers of high temporalresolution observations (Savage and Davidson 2003, Allen et al. 2007, Carbone and Vargas 2008), which in turn present the opportunity to move towards a more predictive understanding of the key mechanisms influencing $\mathrm{R}_{\mathrm{s}}$. Researchers are now able to continuously monitor $\mathrm{CO}_{2}$ concentrations at multiple soil depths (Hirano et al. 2003) as well as calculate $\mathrm{CO}_{2}$ production throughout the soil profile (Davidson and Trumbore 1995, Risk et al. 2002, Vargas and Allen 2008c). The understanding of changes in soil $\mathrm{CO}_{2}$ concentrations is important for soil $\mathrm{CO}_{2}$ dynamics because changes in $\mathrm{CO}_{2}$ concentrations influence soil $\mathrm{CO}_{2}$ production as well as $\mathrm{R}_{\mathrm{s}}$ (Simunek and Suarez 1993). Along with continuous measurements of soil $\mathrm{CO}_{2}$, it is just as critical to incorporate frequent observations of fine root and EM fungal dynamics (Misson et al. 2006, Vargas and Allen 2008a, Stewart and Frank 2008). Fine root and EM rhizomorphs rapidly respond to climatic events (Heinemeyer et al. 2007, Vargas and Allen 2008a), and as a result it is important to understand how their dynamics might influence $\mathrm{CO}_{2}$ concentrations throughout the soil profile. Therefore, measurements of fine root and EM rhizomorph dynamics, soil $\mathrm{CO}_{2}$ and environmental factors should be undertaken on similar temporal scales to better understand the biophysical interactions influencing soil $\mathrm{CO}_{2}$ dynamics.

In this study, although we estimate $\mathrm{R}_{\mathrm{s}}$, we focused on developing models to predict $\mathrm{CO}_{2}$ production because it provides a more desirable indicator of the biological activity in the soil, whereas the efflux of $\mathrm{CO}_{2}$ from the soil surface includes complex parameters describing the interface between soil and the atmosphere (Chen et al. 2005). Furthermore, it is difficult to relate a specific depth of soil temperature when developing models to predict $R_{s}$, but when developing models to predict soil 
$\mathrm{CO}_{2}$ production we can use the temperature at the depth which soil $\mathrm{CO}_{2}$ production was calculated using the gradient flux method (Simunek and Suarez 1993). Here, we combined high frequency observations from minirhizotron images with data from an array of soil sensors to examine relationships between environmental factors (photosynthetically active radiation (PAR), soil temperature and moisture), biotic factors (production of fine roots and EM rhizomorphs), and soil $\mathrm{CO}_{2}$ dynamics $\left(\mathrm{CO}_{2}\right.$ production and $\mathrm{CO}_{2}$ concentrations) in a mixed conifer forest. By using minirhizotron cameras we were able to non-destructively observe in situ root and EM rhizomorph dynamics throughout the soil profile as described in previous studies (Hendrick and Pregitzer 1996, Johnson et al. 2001, Treseder et al. 2005). Additionally, the field site has an array of environmental soil sensors collecting continuous data at multiple depths (see Allen et al. 2007). Using structural equation modeling we constructed a hypothesized model to test causal relationships among environmental factors, biotic factors, and soil $\mathrm{CO}_{2}$ dynamics without disturbing the environment (Ullman 2001). Our objectives were: 1) to determine how seasonal changes in environmental factors affect fine root and EM rhizomorph production; and 2) to determine the relative importance of fine root and EM rhizomorph production on seasonal variation in soil $\mathrm{CO}_{2}$ concentrations and $\mathrm{CO}_{2}$ production throughout the soil profile. We hypothesized that the production of soil $\mathrm{CO}_{2}$ is more tightly coupled to EM rhizomorph production than the production of fine roots. This hypothesis is supported by the fact that soil $\mathrm{CO}_{2}$ dynamics and EM rhizomorph production are strongly influenced by rapid changes in soil temperature and moisture (Heinemeyer et al. 2007, Vargas and Allen 2008a), whereas fine root production respond slower to changes in environmental conditions because of the greater carbon and nutrient costs associated with the production of fine roots (Smith and Read 1997).

\section{Materials and methods}

Study site

The study was conducted at the University of California James San Jacinto Mountain Reserve, a Natural Reserve System field station of the University of California (www.jamesreserve.edu). The Reserve is a mixed conifer forest at $1640 \mathrm{~m}$ in the San Jacinto Mountains, California, USA. Most of the precipitation occurs between November and April; with a mean annual precipitation of $640 \mathrm{~mm}$. Dominant trees at our site include Quercus kelloggii Newb. (California black oak), Pinus lambertiana Dougl. (Sugar Pine) and Arctostaphylos pringlei Parry (Manzanita). The Reserve has served as the Terrestrial Ecology Observing Systems field site for the Center for Embedded Networked Sensing (CENS, http://research.cens.ucla. edu) with the goals to research and develop new environmental sensing technologies for ecological observations (Allen et al. 2007, Hamilton et al. 2007).

Image collection and analysis

In October 2003, we installed an array of six minirhizotron tubes, $5 \mathrm{~cm}$ in diameter and $1 \mathrm{~m}$ long, in a $40 \mathrm{~m}^{2}$ area as described in Vargas and Allen (2008a). We allowed roots and EM rhizomorphs to recolonize the soil surrounding the tubes for two years before images were collected. The images were collected using a minirhizotron microscope (BTC-10 and I-cap software, Bartz Technology) fitted to a laptop computer. Images from all tubes were collected in weekly campaigns between February 2006 and February 2007, with a total of 59 sampling dates or "minirhizotron sessions" at intervals that varied from one day to one month. On average we collected 52 vertical images per tube by inserting the minirhizotron until it reached the bottom of the tube and then moved the camera upward at increments of $1.3 \mathrm{~cm}$. A total of 313 images were collected per day and stored as JPEG files. This high sampling frequency between "minirhizotron sessions" is critical for examining fine root and EM fungal dynamics (Stewart and Frank 2008, Vargas and Allen 2008a).

Images from the minirhizotron camera provided good resolution to accurately identify fine roots, EM root tips (Majdi and Nylund 1996) and EM rhizomorphs (Treseder et al. 2005). Ectomycorrhizal rhizomorphs were identified morphologically, as angular-branching, filamentous structures emanating from EM root tips. Additionally, most rhizomorphic fungi located in the mineral soil tend to be ectomycorrhizal, not saprobic (Dickie et al. 2002), and molecular characterization of rhizomorphic fungi at our study site indicates that these fungi are known EM species (Glass and Allen, unpublished data). For 
each minirhizotron tube, fine root and EM rhizomorph production was determined for each day images were taken as the number of newly appearing roots and rhizomorphs, similar to how Majdi and Nylund (1996) classified "new" roots. We chose only fine root and EM rhizomorph production because these structures are likely to be metabolically active and therefore influence soil $\mathrm{CO}_{2}$ concentrations and in turn soil $\mathrm{CO}_{2}$ production. However, we are aware that persistent roots and EM rhizomorphs also contribute to $\mathrm{CO}_{2}$ production through basal metabolism, and therefore our results may underestimate the importance of fine roots and EM rhizomorphs on soil $\mathrm{CO}_{2}$ dynamics.

Micrometeorological data and soil $\mathrm{CO}_{2}$

In November 2004, we deployed four soil sensor arrays within our $40 \mathrm{~m}^{2}$ study area as described in Allen et al. (2007). Each soil sensor array consisted of a suite of environmental sensors placed at three depths $(2,8,16 \mathrm{~cm})$. At each depth we measured soil temperature, soil moisture (ECHO, Decagon Inc.) and $\mathrm{CO}_{2}$ concentrations using solid-state $\mathrm{CO}_{2}$ sensors (CARBOCAP model GMT 220, Vaisala, Finland). In addition, we measured photosynthetically active radiation (PAR) at a height of $2 \mathrm{~m}$ (S-LIA-M003, Onset Computer Corporation, Bourne, Massachusetts, USA). All environmental variables were recorded at five minute intervals.

The efflux of $\mathrm{CO}_{2}$ from the soil surface was calculated using the $\mathrm{CO}_{2}$ gradient flux method based on $\mathrm{CO}_{2}$ concentrations within the soil profile (see Vargas and Allen 2008a). Briefly, the flux of $\mathrm{CO}_{2}$ between any two layers in the soil profile was calculated by Fick's law of diffusion. Diffusivity of $\mathrm{CO}_{2}$ in the soil profile was calculated using the Moldrup model (Moldrup et al. 1999). Assuming a constant rate of $\mathrm{CO}_{2}$ production in the soil profile, $\mathrm{R}_{\mathrm{s}}$ can be calculated as:

$R s=\frac{z_{i+1} F_{i}-z_{i} F_{i+1}}{z_{i+1}-z_{i}}$

where $F_{i}$, and $F_{i+1}$ are $\mathrm{CO}_{2}$ effluxes $\left(\mu \mathrm{mol} / \mathrm{m}^{2} \mathrm{~s}\right)$ at depths $z_{i}$ and $z_{i+1}(\mathrm{~m})$, respectively (Baldocchi et al. 2006). We estimated $F_{i}$ at two depth intervals, between 2 to $8 \mathrm{~cm}$ and 8 to $16 \mathrm{~cm}$. Once $F_{i}$ has been calculated for discrete layers in the soil profile, soil $\mathrm{CO}_{2}$ production was then calculated from the difference between the effluxes across the two depth intervals as a flux divergence (Simunek and Suarez 1993):

$P_{i}=\frac{F_{i}-F_{i+1}}{z_{i+1}-z_{i}}$

where $P_{i}$ is soil $\mathrm{CO}_{2}$ production $\left(\mu \mathrm{mol} / \mathrm{m}^{3} \mathrm{~s}\right)$ at depth $i$. Because $\mathrm{CO}_{2}$ production was calculated from the difference in efflux between $2-8 \mathrm{~cm}$ and $8-16 \mathrm{~cm}$, we defined $\mathrm{CO}_{2}$ production at $8 \mathrm{~cm}$ depth. Calculating $\mathrm{R}_{\mathrm{s}}$ using the gradient flux method has been validated using the chamber method (LI-8100, Li-COR Biosciences, Inc., Lincoln, NE) at multiple temporal scales at our study site (Vargas and Allen 2008a, b).

Statistical analysis

Root production, EM rhizomorph production, and environmental data were subjected to a nonparametric Mann-Whitney $U$ test to determine significant differences $(\alpha<0.05)$ between the growing season (April-August) and the rest of the year. Aboveground $\mathrm{CO}_{2}$ assimilation rates at our study site are significantly higher between April and August compared to the rest of the year (Goode and Allen, unpublished data). Furthermore, this time period of high carbon assimilation corresponds to when oaks in California are photosynthesizing (Ma et al. 2007). We therefore wanted to look at seasonal differences between the growing season (April-August) and the rest of the year.

Because of the time intervals between minirhizotron images, we are uncertain about the exact dates of root and rhizomorph production. We therefore examined different running averages in the environmental data to determine the best correlation between root and rhizomorph production and environmental data. Pearson correlation coefficients were calculated and compared to determine the best running average for the environmental data. Averages included (a) mean daily averages for the same date minirhizotron images were taken $\left(\mathrm{T}_{\mathrm{i}}\right)$, (b) the mean daily average of $\mathrm{T}_{\mathrm{i}}$ and the day before the minirhizotron images were taken $\left(\mathrm{T}_{\mathrm{A} 1}=\left(\mathrm{T}_{\mathrm{i}}+\mathrm{T}_{\mathrm{i}-1} / 2\right)\right)$, (c) the mean daily average between $T_{i}$ and two days before the minirhizotron images were taken $\left(\mathrm{T}_{\mathrm{A} 2}=\left(\mathrm{T}_{\mathrm{i}}+\mathrm{T}_{\mathrm{i}-1}+\right.\right.$ $\left.T_{i-2} / 3\right)$ ), and (d) the mean daily average between $T_{i}$ and three days before the minirhizotron images were taken $\left(\mathrm{T}_{\mathrm{A} 3}=\left(\mathrm{T}_{\mathrm{i}}+\mathrm{T}_{\mathrm{i}-1}+\mathrm{T}_{\mathrm{i}-2}+\mathrm{T}_{\mathrm{i}-3} / 4\right)\right)$. Statistical analyses were performed using JMP Version 3.2.2 (SAS Institute, Cary, North Carolina, USA). 
Structural equation modeling (SEM) was used to test causal relationships among PAR, soil temperature, soil moisture, root and rhizomorph production on soil $\mathrm{CO}_{2}$ concentrations or $\mathrm{CO}_{2}$ production (Ullman 2001). This statistical method can be seen as a multiple regression approach in which interactions and nonlinearities are taken into account into the model. Furthermore, one of the strengths of this method is the ability to include latent variables (unmeasured variables) which are estimated in the model from measured variables. We constructed a hypothetical model based on first principles where: a) variations in PAR, soil temperature and moisture directly influence variation in root and rhizomorph production; b) variations in PAR, soil temperature, soil moisture, and root and rhizomorph production directly influence variation in soil $\mathrm{CO}_{2}$ dynamics; and c) variations in PAR, soil temperature and moisture indirectly influence soil $\mathrm{CO}_{2}$ dynamics through their effect on root and rhizomorph production (Fig. 1). When testing for causal relationships among environmental factors, biotic factors, and $\mathrm{CO}_{2}$ concentrations at the different soil depths $(2,8$, and $16 \mathrm{~cm})$ we included the production of fine roots and EM rhizomorphs $2 \mathrm{~cm}$ above and below each sensor depth. For example, when investigating interaction at $16 \mathrm{~cm}$ depth we included fine root and EM rhizomorph production between 14 and $18 \mathrm{~cm}$. In contrast, when investigating the causal interactions affecting $\mathrm{CO}_{2}$ production we included fine root and EM rhizomorph production between $2-16 \mathrm{~cm}$ depth because $\mathrm{CO}_{2}$ production was calculated from the difference in effluxes between $2-8 \mathrm{~cm}$ and $8-16 \mathrm{~cm}$. Because $\mathrm{CO}_{2}$ production was defined at $8 \mathrm{~cm}$ depth we used soil temperature and moisture at $8 \mathrm{~cm}$ depth in our model investigating the causal interactions affecting soil $\mathrm{CO}_{2}$ production. We used the AMOS 5.0 software package (Smallwaters Corporation, Chicago, Illinois., USA) to design the model, and to calculate path coefficients, squared multiple correlations, and overall model fit. To test for collinearity among predictor variables we used variance inflation factors and collinearity condition indices for each predictor variable against the remaining predictors (Petraitis et al. 1996). Collinearity occurs when independent variables are highly correlated and may cause coefficient estimates to be less precise (but see O'Brien 2007). Finally, the $\chi^{2}$ goodness-of-fit statistic was used to determine significant results $(P<0.05)$.

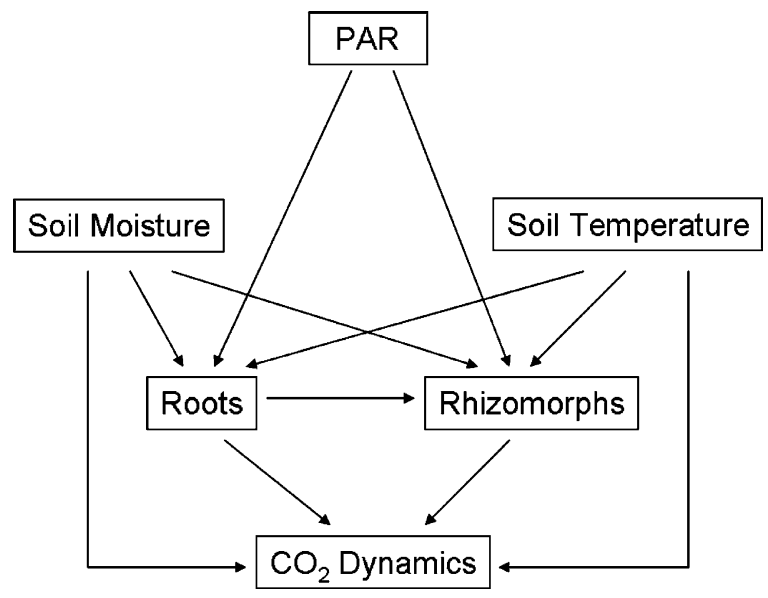

Fig. 1 Path diagram demonstrating the hypothesized causal relationships among environmental factors (PAR, soil temperature and moisture), biotic factors (fine root and EM rhizomorph production), and soil $\mathrm{CO}_{2}$ dynamics $\left(\mathrm{CO}_{2}\right.$ concentrations and $\mathrm{CO}_{2}$ production). Each arrow signifies a hypothesized direct causal relationship in the direction of the arrow. Indirect effects occur if one variable is linked to another via an intermediate variable (e.g. soil moisture and soil temperature can have indirect effects on soil $\mathrm{CO}_{2}$ dynamics through their interaction with fine roots and EM rhizomorphs)

When the $\chi^{2}$ statistic did not show significant differences $(P>0.05)$ between observed and expected correlations matrices the model was considered to be a good fit.

Cross-correlation analyses were used to identify time-lag effects between EM rhizomorph or fine root production and soil $\mathrm{CO}_{2}$ production using MATLAB R2007a (The MathWorks Inc., Natik, Massachusetts, USA). Cross-correlation analysis is a measure of similarity between two different measurements as a function of a time-lag applied to one of them (Nielsen and Wendroth 2003). Therefore, by using this type of analysis we were able to investigate temporal relationships between changes in EM rhizomorph or fine root production and soil $\mathrm{CO}_{2}$ production. We performed these analyses with daily mean values for each one of the measurement days (minirhizotron sessions) of the mentioned variables.

\section{Results}

From among all minirhizotron tubes, including all depths, we observed a total of 190 EM rhizomorphs and 58 fine roots produced during this study. When comparing among seasons, we found significantly 
higher number of fine roots and EM rhizomorphs being produced during the growing season compared to the rest of the year $(0.76 \pm 0.14$ structures produced per tube compared to $0.14 \pm 0.10$ structures produced per tube, mean \pm SE respectively; Fig. $2 \mathrm{a} ; \chi^{2}=19.01$, $P<0.001)$. Seasonal differences were especially evident in EM rhizomorph production, where the production of EM rhizomorphs was nearly seven times greater during the growing season compared to the rest of the year $(1.23 \pm 0.27$ rhizomorphs produced per tube compared to $0.18 \pm 0.20$ rhizomorphs produced per tube, respectively; $\chi^{2}=10.96, P<0.001$ ). Root production was also significantly higher during the growing season compared to the rest of the year $(0.29 \pm 0.07$ roots produced per tube compared to $0.10 \pm 0.05$ roots produced per tube, respectively; $\chi^{2}=$ 10.96, $P<0.01)$.

We also observed seasonal variation in environmental factors during the study (Fig. 2a, b). Mean daily PAR values ranged from a low of $11 \mu \mathrm{mol} / \mathrm{m}^{2} \mathrm{~s}$ to a high
$405 \mu \mathrm{mol} / \mathrm{m}^{2}$ s (Fig. 2a) and were nearly twice as great during the growing season (305. $7 \pm 6.7 \mu \mathrm{mol} / \mathrm{m}^{2} \mathrm{~s}$ compared to $165.7 \pm 5.3 \mu \mathrm{mol} / \mathrm{m}^{2} \mathrm{~s}$, respectively; $\chi^{2}=$ $158.8, \mathrm{df}=1, P<0.001)$. Mean daily soil temperatures at $8 \mathrm{~cm}$ were significantly higher during the growing season compared to the rest of the year $\left(16.6 \pm 0.4^{\circ} \mathrm{C}\right.$ and $7.7 \pm 0.3^{\circ} \mathrm{C}$, respectively; $\chi^{2} 154.3$, df $=1, P<$ 0.001). Soil temperatures did not start increasing until the last week in April and after four months of continuous increase, soil temperatures peaked in late August $\left(24.7^{\circ} \mathrm{C}\right)$ and gradually declined during the fall months (Fig. 2b). We observed two peaks in soil temperature during the winter months; one in early January (8-11) and the other in early February 2007 (10-17). Soil moisture at $8 \mathrm{~cm}$ was not significantly different between the growing season and the rest of the year $\left(\chi^{2}=1.6, \mathrm{df}=1, P=.21\right)$ and averaged $10.75 \%$. On August 17, our field site experienced a significant monsoon rain event, which accounted for the observed pulse in soil moisture (Fig. 2b).
Fig. 2 Seasonal trends in biotic factors and environmental factors in a mixed conifer forest from February 2006 to February 2007. (a) Total fine root and EM rhizomorph production within the soil profile and mean daily PAR (b) Mean daily soil temperature and moisture at $8 \mathrm{~cm}$ depth to show seasonal trends. All environmental data represent mean daily averages from four sensor nodes within our study site. Arrows indicate dates with the highest EM rhizomorph production. Hatched area corresponds to the growing season (April-August)

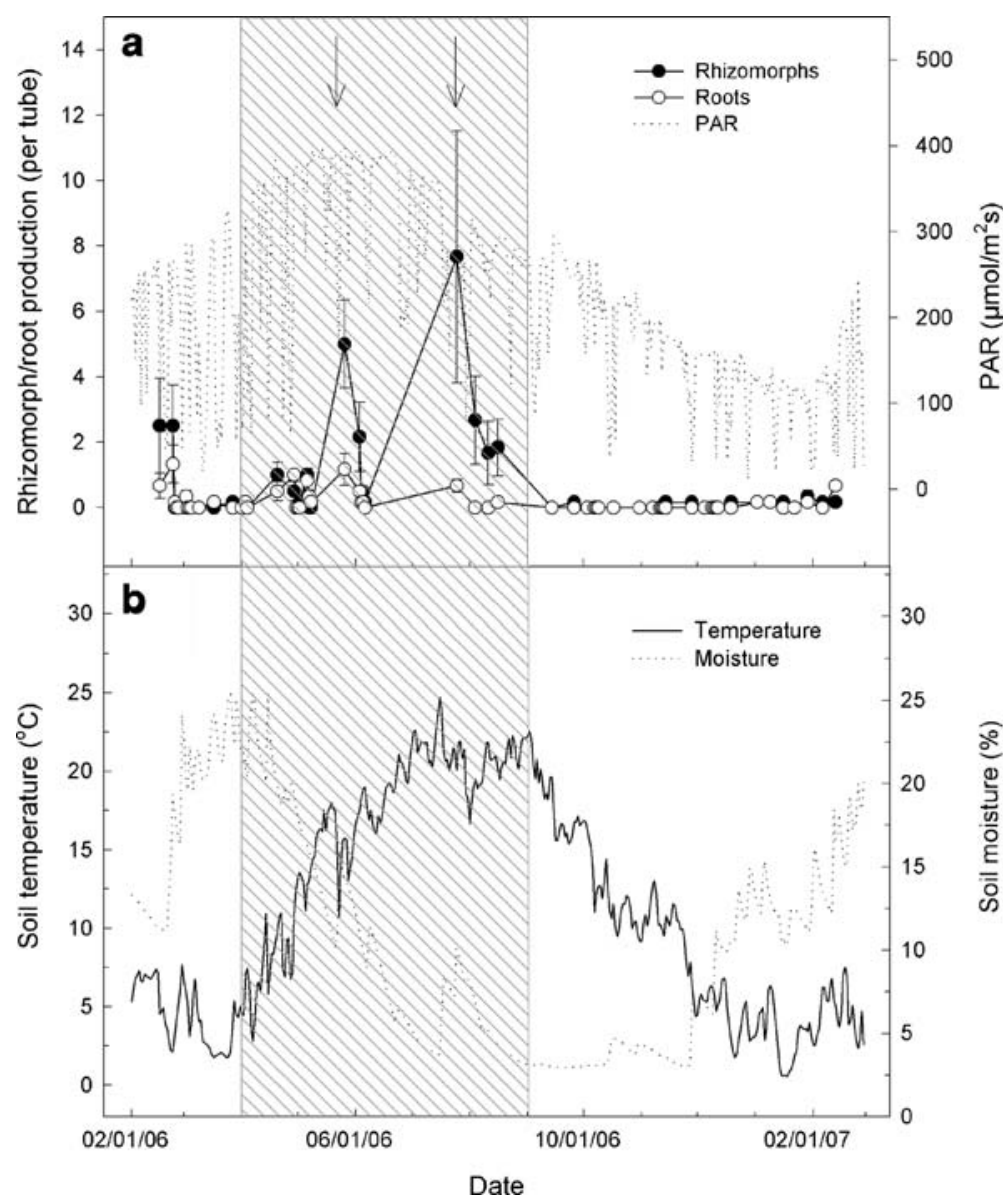


We also observed strong seasonal variation in soil $\mathrm{CO}_{2}$ concentrations and $\mathrm{CO}_{2}$ production $\left(P_{i}\right)$ throughout the study (Fig. 3a, b). Mean daily soil $\mathrm{CO}_{2}$ production was roughly twice as great during the growing season compared to the rest of the year (17.6 \pm $0.4 \mu \mathrm{mol} \mathrm{CO} 2 / \mathrm{m}^{3} \mathrm{~s}$ and $9.1 \pm 0.3 \mu \mathrm{mol} \mathrm{CO} \mathrm{CO}_{2} / \mathrm{m}^{3} \mathrm{~s}$, respectively; $\chi^{2}=195.0$, df $=1, P<0.001$ ). Throughout the study, there were four notable peaks in $\mathrm{CO}_{2}$ production. The first two peaks occurred during the growing season, and corresponded to rain events (Fig. 2b) and the two dates with the highest EM rhizomorph production (Fig. 2a). The other two peaks in $\mathrm{CO}_{2}$ production occurred in January and February 2007 (Fig. 3b) and corresponded to pulses of increased soil temperature (Fig. 2b). $\mathrm{R}_{\mathrm{s}}$ ranged from $0.6 \mu \mathrm{mol}$ $\mathrm{CO}_{2} / \mathrm{m}^{2} \mathrm{~s}$ to $5.8 \mu \mathrm{mol} \mathrm{CO}_{2} / \mathrm{m}^{2} \mathrm{~s}$ throughout the year, with significantly higher rates during the growing session compared to the rest of the year $(3.1 \pm 0.1$ $\mu \mathrm{mol} \mathrm{CO}_{2} / \mathrm{m}^{2} \mathrm{~s}$ and $1.4 \pm 0.1 \mu \mathrm{mol} \quad \mathrm{CO}_{2} / \mathrm{m}^{2} \mathrm{~s}$, respectively; $\left.\chi^{2}=231.8, \mathrm{df}=1, P<0.001\right)$. There was a significant correlation between soil $\mathrm{CO}_{2}$ production $\left(P_{i}\right)$ at $8 \mathrm{~cm}$ depth and $\mathrm{R}_{\mathrm{s}}(\mathrm{r}=0.90, P<0.01)$ suggesting a direct relationship between $\mathrm{CO}_{2}$ production and $\mathrm{R}_{\mathrm{s}}$.

When comparing correlation coefficients using different running averages in the environmental data, we found that the highest overall coefficients were from the running average of two days before minirhizotron images were taken $\left(\mathrm{T}_{\mathrm{A} 2}\right)$. We therefore used this running average $\left(\mathrm{T}_{\mathrm{A} 2}\right)$ for all environmental data in subsequent structural equation modeling (SEM) analysis. In contrast, the mean daily averages of environmental data corresponding to the same date minirhizotron images were taken $\left(\mathrm{T}_{\mathrm{i}}\right)$ had the lowest overall correlation coefficients.
Fig. 3 Seasonal trends in $\mathrm{CO}_{2}$ dynamics throughout the soil profile. (a) Mean daily soil $\mathrm{CO}_{2}$ concentrations at three depths $(2,8$, $16 \mathrm{~cm}$ ) throughout the soil profile (b) Mean daily $\mathrm{CO}_{2}$ production $\left(P_{i}\right)$ determined at $8 \mathrm{~cm}$ depth (see Methods). All $\mathrm{CO}_{2}$ concentration and $\mathrm{CO}_{2}$ production values represent mean daily averages from four sensor nodes within our study site. Arrows indicated the four peaks in $\mathrm{CO}_{2}$ production. Hatched area corresponds to the growing season (April-August)

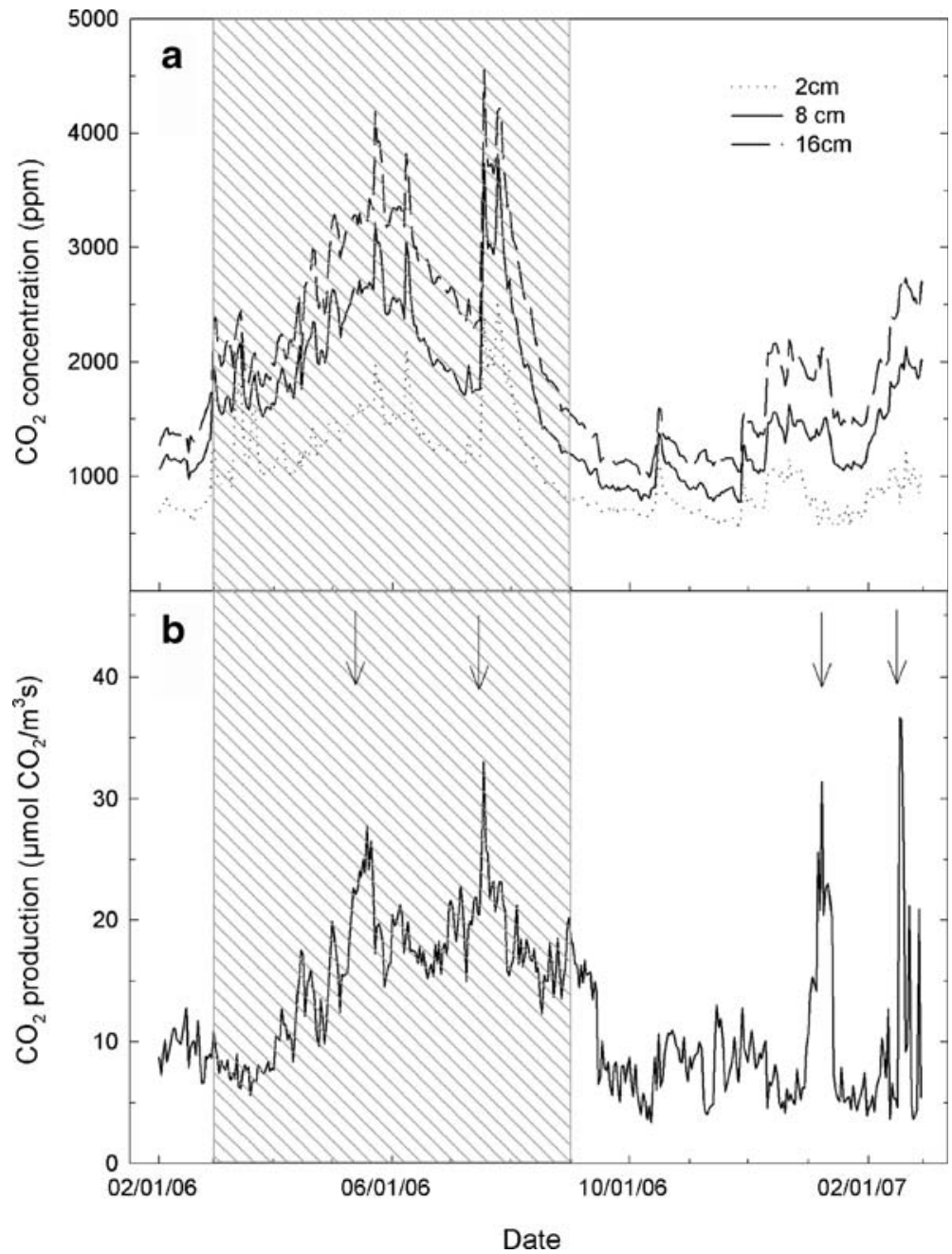


Using SEM we tested for causal relationships between environmental factors and biotic factors on soil $\mathrm{CO}_{2}$ concentration throughout the soil profile. At $2 \mathrm{~cm}$ depth, the observed and expected correlation matrices did not differ significantly $\left(\chi^{2}=1.96 ; P=\right.$ 0.16 ), indicating that the model was a good fit (Fig. 4a). According to our model, we could account for $70 \%$ of the variation in soil $\mathrm{CO}_{2}$ concentrations with direct positive effects from both soil temperature and soil moisture. At this depth, our model accounted for $22 \%$ of the variation in EM rhizomorph produc-

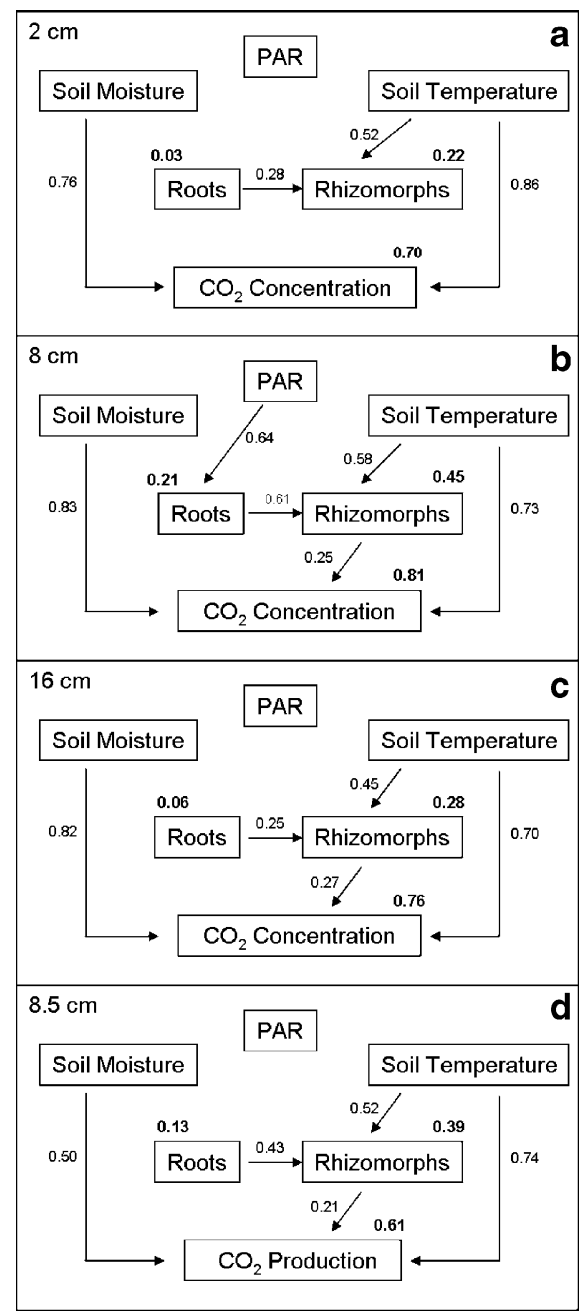

Fig. 4 Structural equation models depicting the causal interactions between environmental factors, biotic factors, and soil $\mathrm{CO}_{2}$ concentrations at (a) $2 \mathrm{~cm}$, (b) $8 \mathrm{~cm}$, (c) $16 \mathrm{~cm}$ and (d) soil $\mathrm{CO}_{2}$ production at $8 \mathrm{~cm}$. Only significant direct effects (arrows) are shown $(P<0.05)$. Numbers in bold above each dependent variable are estimates of the proportion of total variance explained (squared multiple correlations) tion with direct positive effects from both soil temperature and fine root production. In contrast, only $3 \%$ of the variation in fine root production was explained with no significant direct effect from the three environmental factors (Fig. 4a). The biggest variance inflation factor (3.9) was well below the critical limit of 10 and the biggest condition index (11.9) was below the critical limit of 30 (Petraitis et al. 1996).

At $8 \mathrm{~cm}$ depth, our model passed the goodness-of-fit test $\left(\chi^{2}=2.96 ; P=0.09\right.$; Fig. $\left.4 \mathrm{~b}\right)$, with variation inflation factors up to 4.6 and condition indices up to 13.7. At this depth, $81 \%$ of the variation in $\mathrm{CO}_{2}$ concentrations was explained by the model with direct positive effects from EM rhizomorph production, soil moisture, and soil temperature. Our model also accounted for $45 \%$ of the variation in EM rhizomorph production with direct positive effects from both soil temperature and fine root production. In contrast, only $21 \%$ of the variation in fine root production was explained at this depth with a direct positive effect from PAR (Fig. 4b).

At $16 \mathrm{~cm}$ depth, the observed and expected correlation matrices did not differ significantly $\left(\chi^{2}=\right.$ $2.85 ; P=0.09$; Fig. $4 \mathrm{c}$ ), with variation inflation factors up to 4.2 and condition indices up to 13.5. According to our model, we could account for $76 \%$ of the variation in $\mathrm{CO}_{2}$ concentration with direct positive effects from EM rhizomorph production, soil moisture, and soil temperature. At this depth, our model explained $28 \%$ of the variation in EM rhizomorph production with direct positive effects from both soil temperature and fine root production. In contrast, only $6 \%$ of the variation in fine root production was explained at this depth with no significant direct effects from the environmental factors (Fig. 4c).

We used the same hypothesized model and tested for causal relationships between environmental factors and biotic factors on soil $\mathrm{CO}_{2}$ production. The observed and expected correlation matrices did not differ significantly $\left(\chi^{2}=2.21 ; P=0.14\right)$, indicating that the model was a good fit (Fig. 4d). According to our model, $61 \%$ of the variation in soil $\mathrm{CO}_{2}$ production could be explained by direct positive effects from EM rhizomorph production, soil temperature, and soil moisture (Fig. 4d). In addition to directly affecting $\mathrm{CO}_{2}$ production, soil temperature also indirectly affected $\mathrm{CO}_{2}$ production through its interaction on EM rhizomorph production. Fine root 
production did not significantly affect soil $\mathrm{CO}_{2}$ production. The biggest variance inflation factor (4.2) was well below the critical limit of 10 and the biggest condition index (13.2) was well below the critical limit of 30 (Petraitis et al. 1996).

To test for similarity between EM rhizomorph or fine root production and soil $\mathrm{CO}_{2}$ production we used cross-correlation analyses. We found that EM rhizomorph production had a significant $(P<0.05)$ crosscorrelation coefficient with soil $\mathrm{CO}_{2}$ production of nearly 0.5 with a time-lag of zero (Fig. 5). Fine root production, on the other hand, had a significant $(P<$ $0.05)$ cross-correlation coefficient with soil $\mathrm{CO}_{2}$ production of nearly 0.3 with a time-lag larger than zero (Fig. 5). These results indicate that soil $\mathrm{CO}_{2}$ production increased before fine root production, whereas the correlation between EM rhizomorph production and soil $\mathrm{CO}_{2}$ production was maximized with a zero-lag, suggesting a closer relationship between EM rhizomorph production and soil $\mathrm{CO}_{2}$ production, which is consistent with our SEM results (Fig. 4d).

\section{Discussion}

In this study we used soil sensing technology to nondestructively examine the biophysical interactions influencing seasonal soil $\mathrm{CO}_{2}$ dynamics in a mixed conifer forest. During the study there was considerable variation in both soil $\mathrm{CO}_{2}$ production $\left(P_{i}\right)$ and $\mathrm{R}_{\mathrm{s}}$ (Fig. 3b), with significantly higher rates during the growing season compared to the rest of the year. Previous studies have also reported seasonal patterns in $R_{S}$ and attributed increased rates of $R_{S}$ in spring to seasonal variation in photosynthesis and increased rates of autotrophic (root) respiration (Raich and Tufekciogul 2000, Janssens et al. 2001, Baldocchi et al. 2006). However, in this study increased rates of soil $\mathrm{CO}_{2}$ production $\left(P_{i}\right)$ at $8 \mathrm{~cm}$ depth during the growing season correlated with periods of high EM rhizomorph production, whereas fine root production did not appear to significantly affect soil $\mathrm{CO}_{2}$ production. When comparing the total effects of EM rhizomorph production, soil temperature and soil moisture on soil $\mathrm{CO}_{2}$ production we found that $\mathrm{EM}$ rhizomorph production accounted for $\sim 15 \%$ of the variation in $\mathrm{CO}_{2}$ production in our model (Fig. 4d), which is consistent with a recent study by Fahey et al. (2005) where the authors used an indirect mass balance approach and estimated that mycorrhizal fungi accounted for $\sim 12 \%$ of $\mathrm{R}_{\mathrm{s}}$ in a hardwood forest.

The allocation of carbon between fine roots and mycorrhizal fungi is often dependent on environmental conditions. In semi-arid environments such as our research site, water is often limiting for plant growth
Fig. 5 Cross-correlation analyses between daily means of soil $\mathrm{CO}_{2}$ production with daily means of production of fine roots (open circles) and production of EM rhizomorphs (black circles). The $\mathrm{x}$-axis represents the lags in minirhizotron days (see Methods section for details) with a total of 59 days during the studied period. A positive lag means $\mathrm{CO}_{2}$ production values peaked before fine roots or EM rhizomorphs production. Dashed line represents the $95 \%$ probability threshold of significant cross-correlations

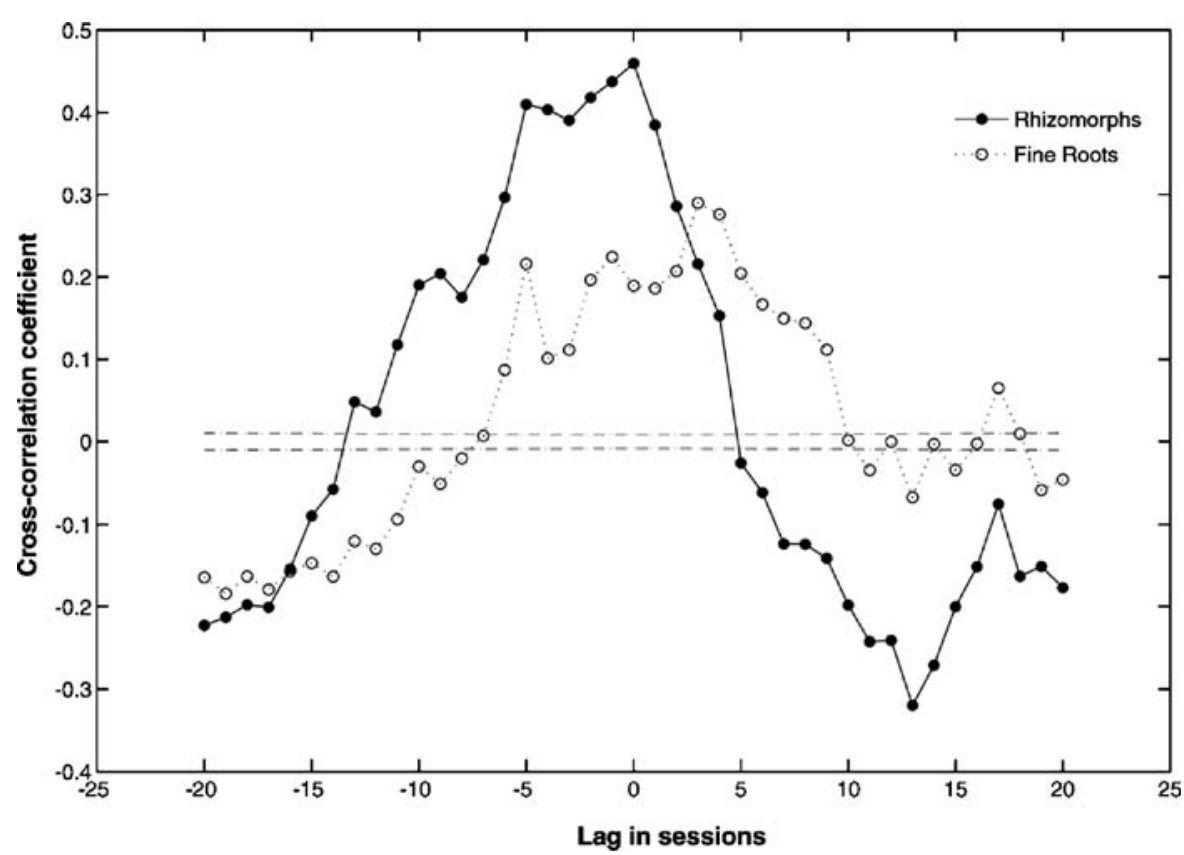


and therefore carbon investment in mycorrhizal fungi may be favored because of their ability to access water and nutrients from the smaller micropores in the soil that are otherwise inaccessible to plant roots (Allen 2007). Throughout this study we observed three times more EM rhizomorphs than roots (Fig. 2a), indicating a substantial carbon investment in EM fungi. Investment in EM fungi was especially pronounced in May, shortly after the leafing out of oaks, as well as in August when temperatures were at their highest and at the same time our study site experienced a significant rain event (Fig. 2). Previously, Vargas and Allen (2008b) reported a seasonal hysteresis effect for $\mathrm{R}_{\mathrm{s}}$ at this study site, with higher rates during the growing season when temperatures were increasing and soil moisture was high. They hypothesized that one plausible explanation for the seasonal hysteresis effect may be due to differences in the relative contributions of growth respiration and maintenance respiration in the autotrophic contribution of $R_{s}$. Results from our study showed significantly higher rates of EM rhizomorph production during the growing season as well as a positive correlation between soil temperature and EM rhizomorph production. Therefore, respiration associated with EM rhizomorph production may, in part, help explain the seasonal hysteresis effect previous observed by Vargas and Allen (2008b).

Overall, our model explained between $70 \%$ and $81 \%$ of the variation in $\mathrm{CO}_{2}$ concentrations throughout the soil profile (Fig. 4). At both $8 \mathrm{~cm}$ and $16 \mathrm{~cm}$ depth, variation in $\mathrm{CO}_{2}$ concentrations was significantly influenced by EM rhizomorph production, soil moisture, and soil temperature. In contrast, variation in $\mathrm{CO}_{2}$ concentrations at $2 \mathrm{~cm}$ depth was significantly influenced by only soil moisture and soil temperature (Fig. 4a). The lack of correlation between biotic factors and $\mathrm{CO}_{2}$ concentrations at $2 \mathrm{~cm}$ depth may be the result of other physical parameters near the soil surface, such as changes in wind patterns and $\mathrm{CO}_{2}$ diffusivity as well as unmeasured biotic factors, such as the activity of fine hyphae and bacteria that influence soil $\mathrm{CO}_{2}$ concentration. In this study, we restricted our definition of biotic factors to the production of fine roots and EM rhizomorphs because these structures can be easily observed using the Bartz minirhizotron camera. However, much of the biomass in the upper layer of the soil profile is composed of decomposers (Glass and Allen, unpublished data) that contribute to the heterotrophic respiration component of $\mathrm{R}_{\mathrm{s}}$. A large contribution from heterotrophic respiration may therefore be responsible for the lack of correlation between biotic factors and $\mathrm{CO}_{2}$ concentrations at $2 \mathrm{~cm}$ depth. Further studies combining automated measurements of soil $\mathrm{CO}_{2}$ production, fine roots, EM rhizomorphs, and destructive microbial measurements are needed to better tease apart the relative contributions from the different components of $\mathrm{R}_{\mathrm{s}}$ at this depth.

Throughout the study, we observed four peaks in soil $\mathrm{CO}_{2}$ production (Fig. 3b). The first two peaks occurred during the growing season and corresponded to dates with the highest EM rhizomorph production, suggesting a rapid response of EM fungi to pulse rain events. This supports earlier findings by Pigott (1982) that certain EM fungi can withstand desiccation in an inactive state, making them ready to respond quickly to rewetting events. Additionally, EM rhizomorphs can be maintained through dry periods by hydraulicallyredistributed water (Querejeta et al. 2003, 2007, 2009), in which EM fungi associated with hosts performing hydraulic lift receive water from their host tree, and transfer this water to mycelium and rhizomorphs. These results also have implications for our understanding of pulses in soil $\mathrm{CO}_{2}$ production as well as $R_{s}$. These pulses have been identified as a burst of decomposition of organic compounds and release of inorganic nitrogen by the rewetting of soils that have been dry for a long period and has been termed the "Birch effect" (Jarvis et al. 2007). This effect is primarily controlled by heterotrophic activity, but our results suggest that autotrophic respiration may also contribute to the "Birch effect" via the rapid production of EM rhizomorphs during these rewetting events. More research is needed to elucidate the potential role of rapid EM rhizomorph production and their contribution to $\mathrm{R}_{\mathrm{s}}$ during rain pulse events.

The other two peaks in $\mathrm{CO}_{2}$ production occurred in January and February of 2007 (Fig. 3b), corresponding to times with very little fine root and EM rhizomorph production. Both peaks in 2007 correspond to times of relatively high soil moisture combined with pulses of increased soil temperature. One plausible explanation for these peaks may be due to quick response of heterotrophic respiration to sudden increases in soil temperature under no water limitation, which is consistent with the well recog- 
nized exponential relationship between heterotrophic respiration and temperature (Hanson et al. 2000).

The relative importance of fine roots and EM fungi on soil $\mathrm{CO}_{2}$ dynamics may be underestimated in this study because we only considered respiration costs associated with the production of new roots and rhizomorphs. Soil $\mathrm{CO}_{2}$ production is also a function of basal metabolism, in addition to the respiration costs of new roots and rhizomorphs. According to our model, fine root production did not significantly affect soil $\mathrm{CO}_{2}$ production, but that does not imply that plant roots do not contribute to soil $\mathrm{CO}_{2}$ production. Instead, the lack of measurable change in root production may indicate that roots are investing in basal metabolism in order to maintain active roots. On the other hand, the smaller biomass and shorter lifespan of EM rhizomorphs could mean that there is minimal basal metabolism without production. Therefore, the production of soil $\mathrm{CO}_{2}$ could be tightly coupled to EM rhizomorph production, but not necessarily coupled to the production of new roots. This difference between basal metabolism and respiration costs associated with production of fine roots and EM rhizomorphs may, in part, help explain the discrepancies between our results and previous results at our study site. Previously, Vargas and Allen (2008a, b) used fine root and EM rhizomorph lengths, which takes into account the respiration costs associated with maintaining functional roots and rhizomorphs (i.e. basal metabolism), and found a positive correlation between fine roots and $\mathrm{R}_{\mathrm{s}}$. Further research is needed to differentiate the respiration costs associated with fine root and EM rhizomorph production versus basal metabolic activity of these structures in regulating soil $\mathrm{CO}_{2}$ dynamics.

The unique aspect of this study was combining high frequency observations of fine root and EM rhizomorph production with data from an array of soil sensors to non-destructively examine the biophysical interactions influencing soil $\mathrm{CO}_{2}$ dynamics. Based on in situ observations, our results showed that increased rates of soil $\mathrm{CO}_{2}$ production were correlated with increased rates of EM rhizomorph production, but not necessarily correlated with fine root production. The difference in carbon allocation between plant roots and EM fungi may have significant consequences to our predictions of soil carbon balance under global climate change. For example, plants are likely to become more nutrientand water-limited under elevated atmospheric $\mathrm{CO}_{2}$ conditions, rather than carbon-limited, and as a result more carbon may be allocated to EM fungi (Allen et al. 2005). Ectomycorrhizal fungi have shorter lifespans than plant roots, and as a result EM fungi may represent what Heinemeyer et al. (2007) described as a $\mathrm{CO}_{2}$ "overflow tap." In this scenario, surplus carbon invested in EM fungi is quickly returned to the atmosphere, thereby limiting expected carbon sequestration under elevated $\mathrm{CO}_{2}$ conditions. Our results support a number of recent studies (Fitter et al. 2000, Treseder and Allen 2000, Alberton et al. 2005) calling for more understanding of the role of mycorrhizal fungi in carbon cycling, and highlight the need to better understand the complex interactions between environmental factors, mycorrhizal fungi, and their contribution to the global carbon cycle (Allen et al. 2007).

Acknowledgements We thank Hector Estrada, Laurel Salzman, Ayesha Sirajuddin, and William Swenson for their help acquiring minirhizotron images. Chris Glover and Kuni Kitajima helped in processing the images. Mike Taggart and Tom Unwin helped on the installation of power supply for our system and maintain the sensor infrastructure. This research was undertaken with funding from the National Science Foundation (grant no. EF-0410408), the Center for Embedded Networked Sensing (grant no. CCR0120778), and the Kearney Foundation. RV was supported by grant DEB-0639235 while writing this manuscript. The authors would like to thank Darrel Jenerette for useful comments on a previous draft of this work.

Open Access This article is distributed under the terms of the Creative Commons Attribution Noncommercial License which permits any noncommercial use, distribution, and reproduction in any medium, provided the original author(s) and source are credited.

\section{References}

Alberton O, Kuyper TW, Gorissen A (2005) Taking a mycocentrism seriously: mycorrhizal fungal and plant responses to elevated $\mathrm{CO}_{2}$. New Phytol 167:859-868

Allen MF (2007) Mycorrhizal fungi: highways for water and nutrients in arid soils. Vadose Zone J 6:291-297

Allen MF, Klironomos JN, Treseder KK, Oechel WC (2005) Responses of soil biota to elevated $\mathrm{CO}_{2}$ in a chaparral ecosystem. Ecol Appl 15:1701-1711

Allen MF, Vargas R, Graham EA, Swenson W, Hamilton MP, Taggart M, Harmon TC, Rat'ko A, Rudel PW, Fulkerson B, Estrin DL (2007) Soil sensor technology: life within a pixel. Bioscience 57:859-867

Baldocchi D, Tang J, Xu L (2006) How switches and lags in biophysical regulators affect spatial-temporal variation of soil respiration in an oak-grass savanna. J Geophys Res. doi:10.1029/2005JG000063 
Boone RD, Nadelhoffer KJ, Canary JD, Kaye JP (1998) Roots exert a strong influence on the temperature sensitivity of soil respiration. Nature 396:570-572

Bowden RD, Nadelhoffer KJ, Boone RD, Melillo JM, Garrison JB (1993) Contributions of above ground litter, below ground litter, and root respiration to total soil respiration in a temperate mixed hardwood forest. Can J For Res 23:1402-1407

Carbone MS, Vargas R (2008) Automated soil respiration measurements: new information, opportunities and challenges. New Phytol 177:295-297

Chen D, Molina JAE, Clapp CE, Veterea RT, Palazzo AJ (2005) Corn root influence on automated measurements of soil carbon dioxide concentrations. Soil Sci 170:779-787

Davidson EA, Trumbore SE (1995) Gas diffusivity and production of $\mathrm{CO}_{2}$ in deep soils of the eastern amazon. Tellus Ser B 47:550-565

Davidson EA, Janssens IA, Luo YQ (2006) On the variability of respiration in terrestrial ecosystems: moving beyond $\mathrm{Q}_{10}$. Glob Chang Biol 12:154-164

Dickie IA, Xu B, Koide RT (2002) Vertical niche differentiation of ectomycorrhizal hyphae in soil as shown by TRFLP analysis. New Phytol 156:527-535

Duddridge JA, Malibari A, Read DJ (1980) Structure and function of mycorrhizal rhizomorphs with special reference to their role in water transport. Nature 287:834-836

Edwards NT (1991) Root and soil respiration responses to ozone in Pinus taeda L. seedlings. New Phytol 118:315-321

Eswaran H, van den Berg E, Reich P (1993) Organic carbon in soils of the world. Soil Sci Soc Am J 57:192-194

Ewel KC, Cropper WP, Gholz HL (1987) Soil $\mathrm{CO}_{2}$ evolution in Florida slash pine plantations. II. Importance of root respiration. Can J For Res 17:330-333

Fahey TJ, Tierney GL, Fitzhugh RD, Wilson GF, Siccama TG (2005) Soil respiration and soil carbon balance in a northern hardwood forest ecosystem. Can J For Res 35:244-253

Fitter AH, Heinemeyer A, Staddon PL (2000) The impact of elevated $\mathrm{CO} 2$ and global climate change on arbuscular mycorrhizas: a mycocentric approach. New Phytol 147:179-187

Hamilton M, Graham EA, Rundel PW, Allen MF, Kaiser W, Hansen MH, Estrin DL (2007) New approaches in embedded network sensing for terrestrial ecological observatories. Environ Eng Sci 24:192-204

Hanson PJ, Edwards NT, Garten CT, Andrews JA (2000) Separating root and soil microbial contributions to soil respiration: a review of methods and observations. Biogeochemistry 48:115-146

Heinemeyer A, Hartley IP, Evans SP, De la Fuente JAC, Ineson $\mathrm{P}$ (2007) Forest soil $\mathrm{CO}_{2}$ flux: uncovering the contribution and environmental responses of ectomycorrhizas. Glob Chang Biol 13:1786-1797

Hendrick RL, Pregitzer KS (1996) Temporal and depth-related patterns of fine root dynamics in northern hardwood forests. J Ecol 84:167-176

Hirano T, Kim H, Tanaka Y (2003) Long-term half hourly measurement of soil $\mathrm{CO}_{2}$ concentration and soil respiration in a temperate deciduous forest. J Geophys Res. doi:10.1029/2003JD003766

Högberg P, Högberg MN, Göttlicher SG, Betson NR, Keel SG, Metcalfe DB, Campbell C, Schinderbacher A, Hurry V, Lundmark T, Linder S, Näsholm T (2008) High temporal resolution tracing of photosynthate carbon from the tree canopy to forest soil organisms. New Phytol 177:220-228

Janssens IA, Matteucci HG, Kowalski AS, Buchman N, Epron D, Pilegaard K, Kutsch W, Longdoz B, Grunwald T et al (2001) Productivity overshadows temperature in determining soil ecosystem respiration across European forests. Glob Chang Biol 7:269-278

Jarvis P, Rey A, Petsikos C, Wingate L, Rayment M, Pereira J, Banza J, David J, Miglietta F, Borghetti M, Manca G, Valentini R (2007) Drying and wetting of Mediterranean soils stimulates decomposition and carbon dioxide emission: the "Birch effect". Tree Physiol 27:929-940

Johnson MG, Tingey DT, Phillips DL, Storm MJ (2001) Advancing fine root research with minirhizotrons. Environ Exp Bot 45:263-289

Langley JA, Johnson NC, Koch GW (2005) Mycorrhizal status influences the rate but not the temperature sensitivity of soil respiration. Plant Soil 277:335-344

Law BE, Ryan MG, Anthoni PM (1999) Seasonal and annual respiration of a Ponderosa pine ecosystem. Glob Chang Biol 5:169-182

Ma SY, Baldocchi DD, Xu LK, Hehn T (2007) Inter-annual variability in carbon dioxide exchange of an oak/grass savanna and open grassland in California. Agric For Meteorol 147:157-171

Majdi H, Nylund JE (1996) Does liquid fertilization affect fine root dynamics and lifespan of mycorrhizal short roots? Plant Soil 185:305-309

Misson L, Gershenson A, Tang JW, McKay M, Cheng WX, Goldstein A (2006) Influences of canopy photosynthesis and summer rain pulses on root dynamics and soil respiration in a young ponderosa pine forest. Tree Physiol 26:833-844

Moldrup PT, Olesen T, Yamaguchi P, Schjonning P, Rolston DE (1999) Modeling diffusion and reaction in soils: IX. The Buckingham-Burdine-Campbell equation for gas diffusivity in undisturbed soil. Soil Sci 164:542-551

Nielsen DR, Wendroth O (2003) Spatial and temporal statistics. Sampling field soils and their vegetation. Catena-Verlag, Reiskirchen

O'Brien RM (2007) A caution regarding rules of thumb for variance inflation factors. Qual Quant 41:673-690

Petraitis PS, Dunham AE, Niewiarowski PH (1996) Inferring multiple causality: the limitations of path analysis. Funct Ecol 10:421-431

Pigott CD (1982) Survival of mycorrhiza formed by Cenococcum geophilum Fr in dry soils. New Phytol 92:131-142

Querejeta JI, Egerton-Warburton LM, Allen MF (2003) Direct nocturnal water transfer from oaks to their mycorrhizal symbionts during severe soil drying. Oecologia 134:5564

Querejeta JI, Egerton-Warbutron LM, Allen MF (2007) Hydraulic lift may buffer rhizosphere hyphae against negative effects of severe soil drying in a California oak savanna. Soil Biol Biochem 39:409-417

Querejeta JI, Egerton-Warburton LM, Allen MF (2009) Topographic position modulates the mycorrhizal response of oak trees to inter-annual rainfall variability in a California woodland. Ecology 90:649-662

Raich JW, Schlesinger WH (1992) The global carbon dioxide flux in soil respiration and its relationship to vegetation and climate. Tellus Ser B 44:81-99 
Raich J, Tufekciogul A (2000) Vegetation and soil respiration: correlations and controls. Biogeochemistry 48:71-90

Read DJ (1991) Mycorrhizas in ecosystems. Experientia 47:376-391

Risk D, Kellman L, Beltrami H (2002) Carbon dioxide in soil profiles: production and temperature dependence. Geophys Res Lett. doi:10.1029/2001GLO14002

Savage KE, Davidson EA (2003) A comparison of manual and automated systems for soil $\mathrm{CO}_{2}$ flux measurements: tradeoffs between spatial and temporal resolution. J Exp Bot 54:891-899

Schlesinger WH, Andrews JA (2000) Soil respiration and the global carbon cycle. Biogeochemistry 48:7-20

Simunek J, Suarez DL (1993) Modeling of carbon-dioxide transport and production in soil.1. Model development. Water Resour Res 29:487-497

Smith SE, Read DJ (1997) Mycorrhizal symbiosis, 2nd edn. Academic, London

Söderström B, Read DJ (1987) Respiratory activity of intact and excised ectomycorrhizal mycelial systems growing in unsterilized soil. Soil Biol Biochem 19:231-236

Stewart AM, Frank DA (2008) Short sampling intervals reveal very rapid root turnover in a temperate grassland. Oecologia $157: 453-458$
Stoyan H, De-Polli H, Bohm S, Robertson GP, Paul EA (2000) Spatial heterogeneity of soil respiration and related properties at the plant scale. Plant Soil 222:203-214

Treseder KK, Allen MF (2000) Mycorrhizal fungi have a potential role in soil carbon storage under elevated $\mathrm{CO}_{2}$ and nitrogen deposition. New Phytol 147:189-200

Treseder KK, Allen MF, Ruess RW, Pregitzer KS, Hendrick RL (2005) Lifespan of fungal rhizomorphs under nitrogen fertilization in a pinyon-juniper woodland. Plant Soil 270:249-255

Ullman JB (2001) Structural equation modeling. In: Tabachnick BG, Fidell LS (eds) Using multivariate statistics. Allen and Bacon, Boston, pp 653-771

Vargas R, Allen MF (2008a) Dynamics of fine root, fungal rhizomorphs, and soil respiration in a mixed temperate forest: integrating sensors and observations. Vadose Zone J 7:1055-1064

Vargas R, Allen MF (2008b) Environmental controls and the influence of vegetation type, fine roots and rhizomorphs on diel and seasonal variation in soil respiration. New Phytol 179:460-471

Vargas R, Allen MF (2008c) Diel patterns of soil respiration in a tropical forest after Hurricane Wilma. J Geophys Res. doi:10.1029/2007JG00620 